\title{
Intriguing gastrointestinal properties of bismuth: A folk remedy brought into the realm of clinical and investigative medicine
}

\author{
Seymour Mishkin MD FRCPC FACP
}

$\mathrm{B}$ ismuth subsalicylate (BSS), the use of which was first recorded in 1733 , is highly regarded by practitioners of alternative medicine as well as by well-meaning grandmothers, clinicians and basic scientists (1). In 1900, a pink, winter-green flavoured liquid preparation of BSS, the forerunner to Pepto-Bismol (BSS) (Procter \& Gamble, Ohio), was called 'mixture cholera infantum'. Unlike previous concoctions, this mixture was proven to be a successful treatment for cholera infantum. This product, which gained in popularity steadily, was also effective against 'summer complaint', characterized by acute gastroenteritis. Current therapeutic uses of bismuth salts based on clinical evidence include control of odour in ostomy patients, prophylaxis against travellers' diarrhea, and treatment of various bacterial and viral induced diarrheas, dyspepsia, peptic ulcer disease as well as nonsteriodal anti-inflammatory drug-induced upper-gastrointestinal (GI) injury $(2,3)$. The present love affair with bismuth stems partly from observations that treatment of peptic ulcers with this inexpensive compound results in a lower rate of relapse than that obtained with $\mathrm{H}_{2}$ blockers. This is due to a direct antibacterial action of bismuth on Helicobacter pylori as well as to interference with the epithelial attachment of this organism. A Canadian, randomized clinical trial using colloidal bismuth subcitrate (CBS), together with metronidazole and tetracycline, achieved an eradication rate of $86 \%$ (4). This treatmentregimen is no longer first-line therapy for $H$ pylori because the pooled data fall just below the $80 \%$ cut-off. It has been shown both in vitro and in vivo that bismuth in combination with ranitidine or clarithromycin has a synergistic rather than an additive effect against $H$ pylori (5). In addition, recent preliminary in vitro evidence suggests that bismuth can prevent the resistance of $H$ pylori to metronidazole - an increasing concern for treating physicians. Approval was recently obtained in Canada for a two-week regimen of ranitidine bismuth citrate plus clarythromycin, which achieves eradication rates comparable to those obtained with 'triple therapy' (5). Details regarding actual dosages and duration of treatment for the various helicobacter eradication regimens can be obtained from the Canadian Helicobacter Pylori Consensus Conference (6).

The Dalhousie Helicobacter Pylori Study Group has a definite interest in bismuth compounds. The synthesis of novel bismuth compounds by Dr Neil Burford was spurred on by the realization that the exact chemical structures of both CBS and BSS are unknown. A collaborative study indicated that different bismuth compounds have markedly different in vitro activities against $H$ pylori (7). In a separate study of experimental ulcers in a rat model not involving helicobacter infection, the same group demonstrated that ulcer healing properties depend on the chemical structure of the bismuth compound used $(8,9)$. In a study of colitis in the rat, this group also showed that both BSS and CBS had efficacy in healing colitis (10). This result concurs with results from

Royal Victoria Hospital and McGill University, Montreal, Quebec

Correspondence and reprints: Dr S Mishkin, 4060 rue Sainte-Catherine Ouest, Suite 770, Westmount, Quebec H3Z $2 Z 3$.

Telephone 514-932-2686, fax 514-931-2233,dmishk@po-box.mcgill.ca

Received for publication March 20, 1998. Accepted July 3, 1998 
several recent clinical reports demonstrating efficacy of oral BSS in microscopic colitis (11) and bismuth carbomer enemas in treatment-resistant chronic pouchitis (12).

BSS is almost completely hydrolyzed in the stomach to form bismuth oxychloride and salicylic acid. The bismuth released exerts its cytoprotective action not only by coating the gastric lining but also by stimulating prostoglandin synthesis. Very little bismuth (less than 1\%) is absorbed by the small intestine. In the colon, bismuth salts react with hydrogen sulphide produced by anaerobic bacteria to produce bismuth sulphide, a highly insoluble black salt responsible for the often noted darkening of the stool. This reaction does not interfere with standard tests to detect occult blood. Salicylate derived from BSS is almost completely absorbed from the GI tract. Although there are no reports of salicylate toxicity associated with BSS ingestion, caution should be exercised when BSS is administered to young children, individuals with salicylate sensitivity or bleeding disorders and those taking drugs that have clinically significant interactions with salicylate.

The downside of bismuth relates to the sequestration of this heavy metal in multiple tissue sites (ie, brain, kidney, bone and lung). Between 1973 and 1980, approximately 1000 cases of bismuth-related neurotoxicity were reported in France, Australia, Belgium, Switzerland and Spain. In most cases excessive doses had been consumed for prolonged periods (up to 30 years), hence the concern with long term uninterrupted use of bismuth. Few additional cases have been recorded subsequent to this epidemic, which led to the voluntary withdrawal of CBS from the Canadian marketplace. The Pepto-Bismol product information on the label states that its use should be limited to eight days.

Were it not for the evolution of bismuth from the realm of folk remedy to that of clinical and investigative medicine the mechanisms of its GI properties would never have been documented, and the potential for toxicity after prolonged uninterrupted use would not have been recognized. I advocate that this process be extended to many other seemingly beneficial 'natural preparations'.

\section{REFERENCES}

1. Bierer DW. Bismuth subsalicylate: history, chemistry, and safety. Rev Infect Dis 1990;12(Suppl 1):S3-8.

2. Gorbach SL. Bismuth therapy in gastrointestinal diseases. Gastroenterology 1990;99:863-75.

3. Marshall BJ. The use of bismuth in gastroenterology. The ACG Committee on FDA-Related Matters. American College of Gastroenterology. Am J Gastroenterol 1991;86:16-25.

4. Veldhuyzen van Zanten SJO, Farley A, Marcon N, et al. Efficacy of colloidal bismuth subcitrate, metronidazole, and tetracycline $\mathrm{HCl}$ in eradication of H Pylori. A randomized, placebo-controlled study. Can J Gastroenterol 1998;12(Suppl A):53A. (Abst P9)

5. Bardhan KD, Dallaire C, Eisold H. Ranitidine bismuth citrate with clarithromycin for the treatment of duodenal ulcer. Gut 1997;41:181-6.

6. Hunt R, Thomson ABR. Canadian Helicobacter pylori Consensus Conference. Can J Gastroenterol 1998;12:31-41

7. Burford N, Veldhuyzen van Zanten SJO, Agocs L, et al. Anti-Helicobacter pylori properties of new bismuth compounds. Gastroenterology 1994;106:A59.

8. LeBlanc R, Veldhuyzen van Zanten SJO, Burford N, et al. The efficacy of novel bismuth $(\mathrm{Bi})$ compounds in healing gastric ulceration in the rat varies with chemical structure: Implications for Helicobacter pylori (HP) treatment. Gastroenterology 1995;108:A860.

9. Sandha GS, LeBlanc R, Veldhuyzen van Zanten SJO, Leddin DJ. Mechanism of action of bismuth $(\mathrm{Bi})$ in ulcer healing in the rat a comparison of 2 novel $\mathrm{Bi}$ compounds with commercial colloidal $\mathrm{Bi}$ sub-citrate (CBS). Can J Gastroenterol 1996;10(Suppl A):53A. (Abst PS78)

10. Cleary CE, Peterson TC, Malatjalian DA, Veldhuyzen van Zanten SJO. Comparison of two bismuth compounds and 5-ASA enemas for treatment of TNBS induced experimental colits. Clin Invest Med 1994;17(Suppl 4):B41. (Abst 234)

11. Fine KD, Lee EL. Efficacy of open-label bismuth subsalicylate for the treatment of microscopic colitis. Gastroenterology 1998;114:29-36.

12. Gionchetti P, Rizzello F, Venturi A, et al. Long-term efficacy of bismuth carbomer enemas in patients with treatment-resistant chronic pouchitis. Aliment Pharmacol Ther 1997;11:673-8. 


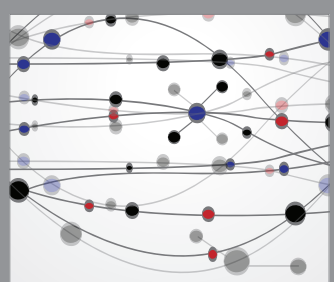

The Scientific World Journal
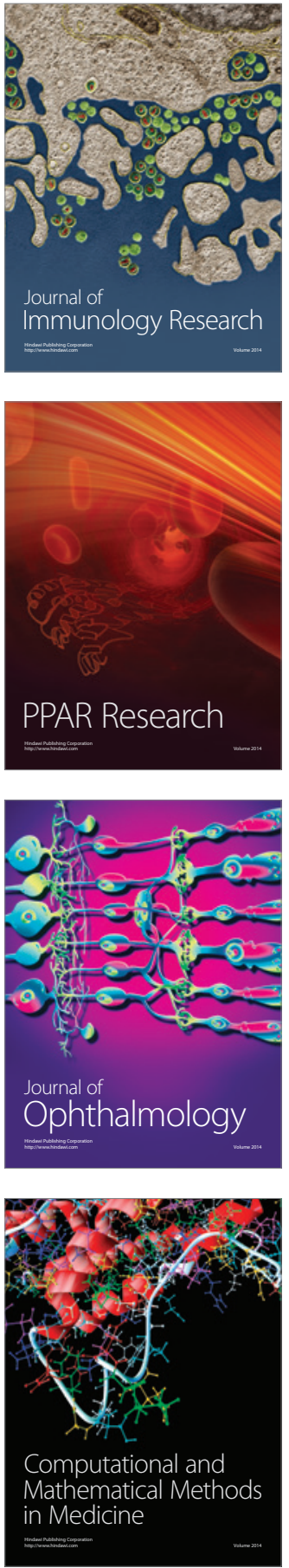

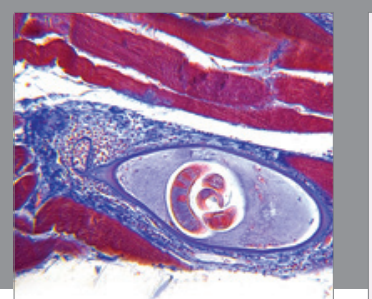

Gastroenterology Research and Practice

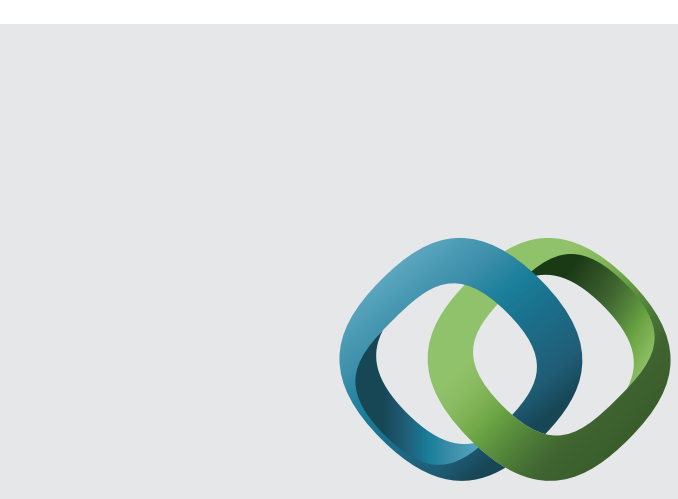

\section{Hindawi}

Submit your manuscripts at

http://www.hindawi.com
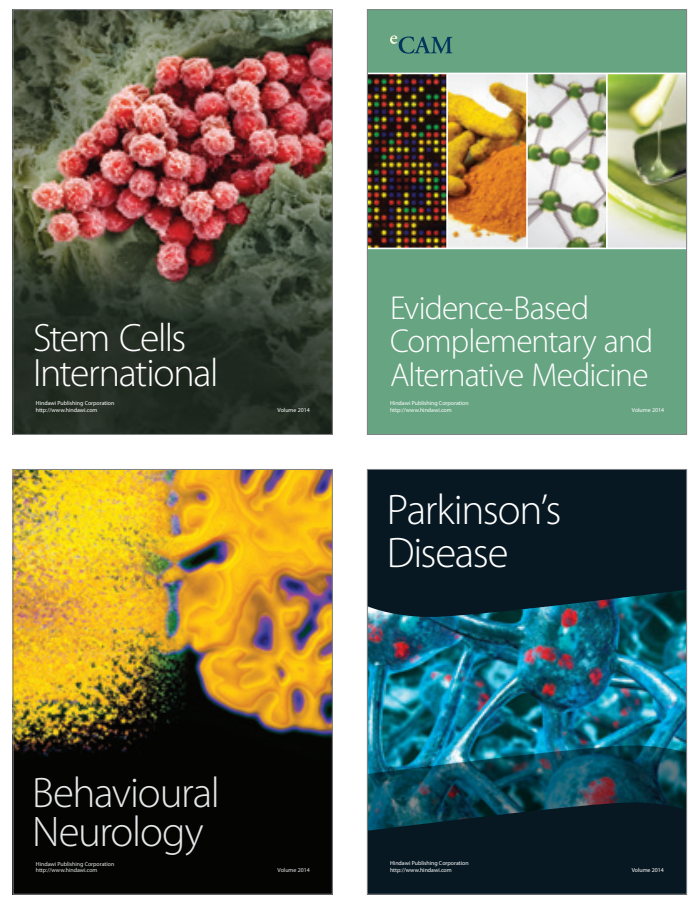
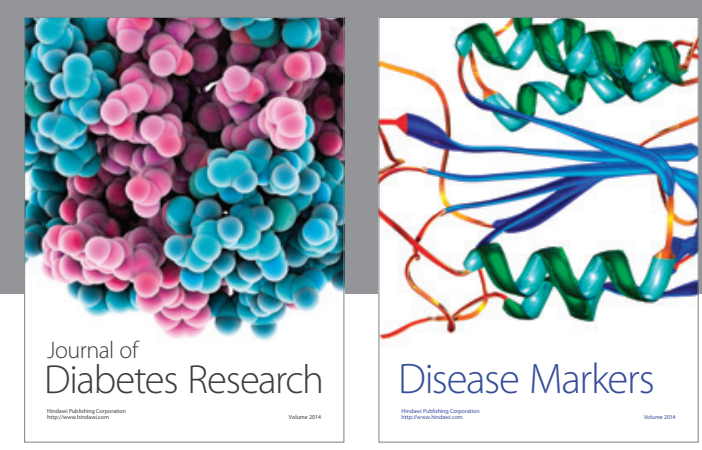

Disease Markers
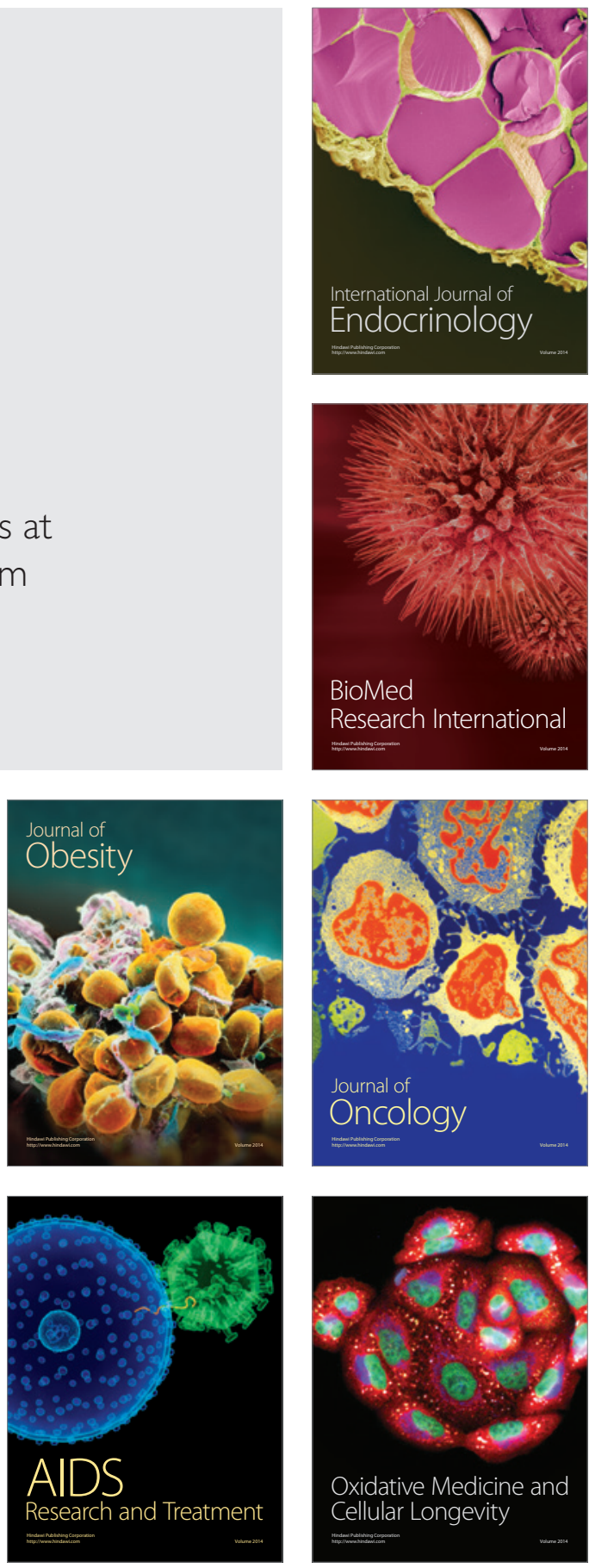